This is the submitted version of the following article:

Nagar B., Balsells M., de la Escosura-Muñiz A., Gomez-Romero P., Merkoçi A.. Fully printed one-step biosensing device using graphene/AuNPs composite. Biosensors and Bioelectronics, (2019). 129. : 238 - . 10.1016/j.bios.2018.09.073,

which has been published in final form at https://dx.doi.org/10.1016/j.bios.2018.09.073 (c) https://dx.doi.org/10.1016/j.bios.2018.09.073. This manuscript version is made available under the CC-BY-NC-ND 4.0 license http://creativecommons.org/licenses/by-nc-nd/4.0/ 


\section{Fully Printed One-Step Biosensing Device Using Graphene/AuNPs}

Composite.

Bhawna Nagar ${ }^{\mathrm{a}, \mathrm{b}}$, Marc Balsells ${ }^{\mathrm{a}}$, Alfredo de la Escosura-Muñiz ${ }^{\mathrm{a}}$, Pedro Gomez-Romero ${ }^{\mathrm{b}}$, and Arben Merkoçi $\mathrm{i}^{\mathrm{a}, c_{*}}$

a Nanobioelectronics and Biosensors group, Catalan Institute of Nanoscience and Nanotechnology (ICN2), CSIC and The Barcelona Institute of Science and Technology, Campus UAB, Bellaterra, 08193 Barcelona, Spain

b Novel Energy-Oriented Materials Group, Catalan Institute of Nanoscience and Nanotechnology (ICN2), CSIC and The Barcelona Institute of Science and Technology, Campus UAB, 08193 Bellaterra, Barcelona (Spain)

'ICREA, Pg. Lluís Companys, 23, Barcelona 08010, Spain

* Corresponding author. Tel.: +34 937374604; e-mail: arben.merkoci@icn2.cat (A.Merkoçi) 
Graphical Abstract

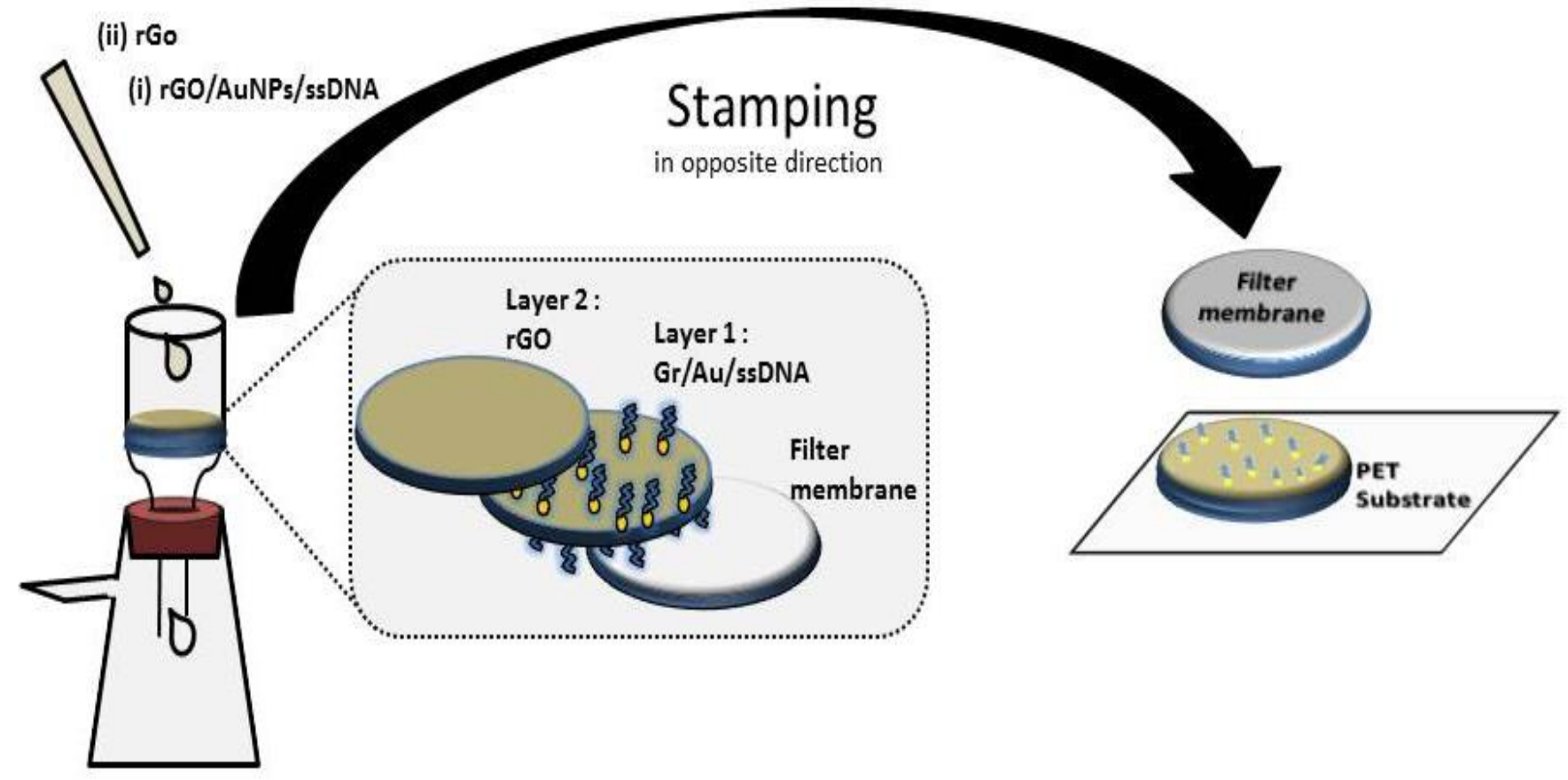




\section{ABSTRACT}

Driven by the growing need of simple, cost efficient and flexible sensing systems, we have designed here a fully printed Reduced Graphene Oxide (rGO) based impedimetric sensor for one step sensing of DNA. The DNA sensor was fabricated by stamping of layered rGO and rGO/gold nanoparticles/single stranded DNA (rGO/AuNPs/ssDNA) composites over PET substrates using wax-printing technique. rGO works as an excellent working electrode, while the AuNPs create a suitable environment for ssDNA immobilization. Counter and reference electrodes were previously screen-printed on the plastic substrate, making thus a compact and highly integrated sensing platform. The change in electron transfer resistance after hybridization with a target ssDNA specific of Coxsackie B3 virus was monitored using electrochemical impedance spectroscopy (EIS), finding a linear response in the range of concentrations $0.01-20 \mu \mathrm{M}$. The novel, simple and straightforward one-step printing process for fabrication of a biosensing device developed keeps in mind the growing need of large scale device manufacturing. The successful proof-of-concept for the detection of DNA hybridization can be extended to other affinity biosensors, taking advantage of the integration of the bioreceptor on the sensor surface. Such ready-to-use biosensor would lead to a onestep electrochemical detection.

KEYWORDS: rGO, Wax stamping, screen printing, Electrochemistry, DNA, biosensing 


\section{INTRODUCTION}

Graphene is a well-known one-atom thick two dimensional carbon layer that possess outstanding inherent properties like high mechanical and chemical stability, high thermal and outstanding electrical and thermal conductivity (Novoselov, K.S. et al, 2004; Geim, A. K. and Novoselov K. S.,2007) . It has a high theoretical surface area of about $2600 \mathrm{~m}^{2} \mathrm{~g}^{-1}$ that is higher than that of carbon or CNTs $\left(10\right.$ or $\left.1315 \mathrm{~m}^{2} \mathrm{~g}^{-1}\right)$. It is $\mathrm{sp}^{2}$ hybridized and the out of plane $\pi$ bonds are responsible for the high conductivity. Although these properties are interesting and highly useful for research purposes in different areas, they vary greatly with the quality of graphene (Chen, X-m. et al, 2011; Bollella, P et al., 2017) that is, number of layers, sheet size, degree of oxidation or defects, all of which depend in turn of the production procedures. Indeed, graphene materials with varied quality and price can be prepared in different ways considering the end application; broadly by mechanical or chemical exfoliation of graphite, vapor deposition or epitaxial growth etc. (Lee, H. C.2017). All this has made possible the use of graphene in broad range of applications (Randviir, E.P. et al, 2014) like solar cells (Roy-Mayhew, J. D. and I. A. Aksay, 2014), energy storage (Dubal, D. P. et al, 2017; Li, X. and L. Zhi, 2018), electronics (Lee, S.-M. et al, 2015), (bio)sensing (Shao, Y. et al, 2010; Justino, C. I. L. et al, 2017) to name a few. Owing to such great properties of graphene, especially due to its high conductivity and high biomolecule loading as a result of high surface area, it is widely explored in the research of (electrochemical) biosensings (Pumera, M., 2011; Bo, X. et al, 2017 ), for instance, Tzu-YenHuang et al demonstrated the use of rGO composite with single-walled carbon nanotubes as an effective electrode material for electrochemical sening (Huang, T. U. et al, 2013). Apart from this, graphene can interact with the biomolecules using non covalent interactions like $\pi-\pi$ or Hydrogen bonding making it more suitable for sensors application. 
For Two formats are widely followed for DNA sensing taking advantage of rGO, either attaching (labelled or non-labelled) ssDNAs directly over Graphene sheet via $\pi$ - $\pi$ bonding or by modifying Graphene surface by using polymers, nanoparticles etc. that have available groups or sites for binding to the DNA. Most commonly used nanomaterial for this purpose are gold nanoparticles (AuNPs) which are typicaly attached to the modified ssDNA at one end via thiol-Au interactions (Lin, L. et al, 2011; Singh, A., 2013) .

Flexibility and portability are characteristics most expected for wearable electronic systems and is been used in fancy applications like implantable/wearable sensors (Ray, W. J. and Wang. J, 2013; Singh, E. et al, 2017) Joseph , OLEDs (Lee, J. Et al, 2016) , transistors(Seo, J.-H et al, 2016) , energy devices (Nagar, B. et al, 2018) etc. Material of interest is usually printed over a flexible substrate (usually plastics) to make a cost efficient, compatible, flexible and easy to handle or use device. The ability to form nanoscale patterns and features over the flexible substrates offers us the advantage of more sensitivity and precision in the sensing devices along with low cost and easy handling. Several printing techniques like screen printing, inkjet printing, roll-to-roll, wax transfer/stamping technique etc. (Søndergaard, R. et al 2012; Li, J. Et al, 2015; Baptista-Pires, L. Et al, 2016; Mattana, G. and Briand D., 2016) are being used for the fabrication of electrodes. However, it is important to select a particular technique for a particular application. Particularly, our objective is the development of a Point-of-Care (POC) device, which requires a fabrication technique that doesn't need any post printing step for keeping the biomaterial unharmed, being wax stamping technique ideal in this case. POC have been widely used for decades now but is yet continuously refined according the user and manufacturer's needs. The important features to be fulfilled for POCs are (a) ease of fabrication, (b) cost effectiveness and (c) easy handling. The advancements in recent years have provided us with loads of new technological strategies to make improved devices for biorecognition, interactions and sensing (Quesada-Gonzalez, D., Merkoçi, A., 2018) . 
In this work, we used chemically exfoliated graphite as it promotes cost effective, large scale production of Graphene Oxide (GO; graphene sheets containing Oxygenated groups such as epoxides, alcohols or carboxyl groups on the surface or the edges of the sheets). The presence of these groups makes GO water dispersible which further helps in making water based inks for printing purposes. Such material was later reduced to reduced Graphene Oxide (rGO) and mixed with already conjugated gold nanoparticle/single stranded DNA probe (AuNPs/ssDNA). Later, wax stamping technique was applied to create the working electrode pattern made of the rGO/AuNPs/ssDNA composite over already screen-printed counter (carbon) and reference $(\mathrm{Ag} / \mathrm{AgCl})$ electrodes, allowing us to have a ready-to-use one-step electrochemical biosensor This strategy for patterning rGOe composite doesn't require harsh or toxic solvents helping us to get rid of the post printing steps (annealing) that could affect the functioning of the biorecognition element (DNA in this case). At the end, we get a sensing platofrm with uniform patterns integrated with the biorector,which is ready to be tested without any further steps (Figure 1). 


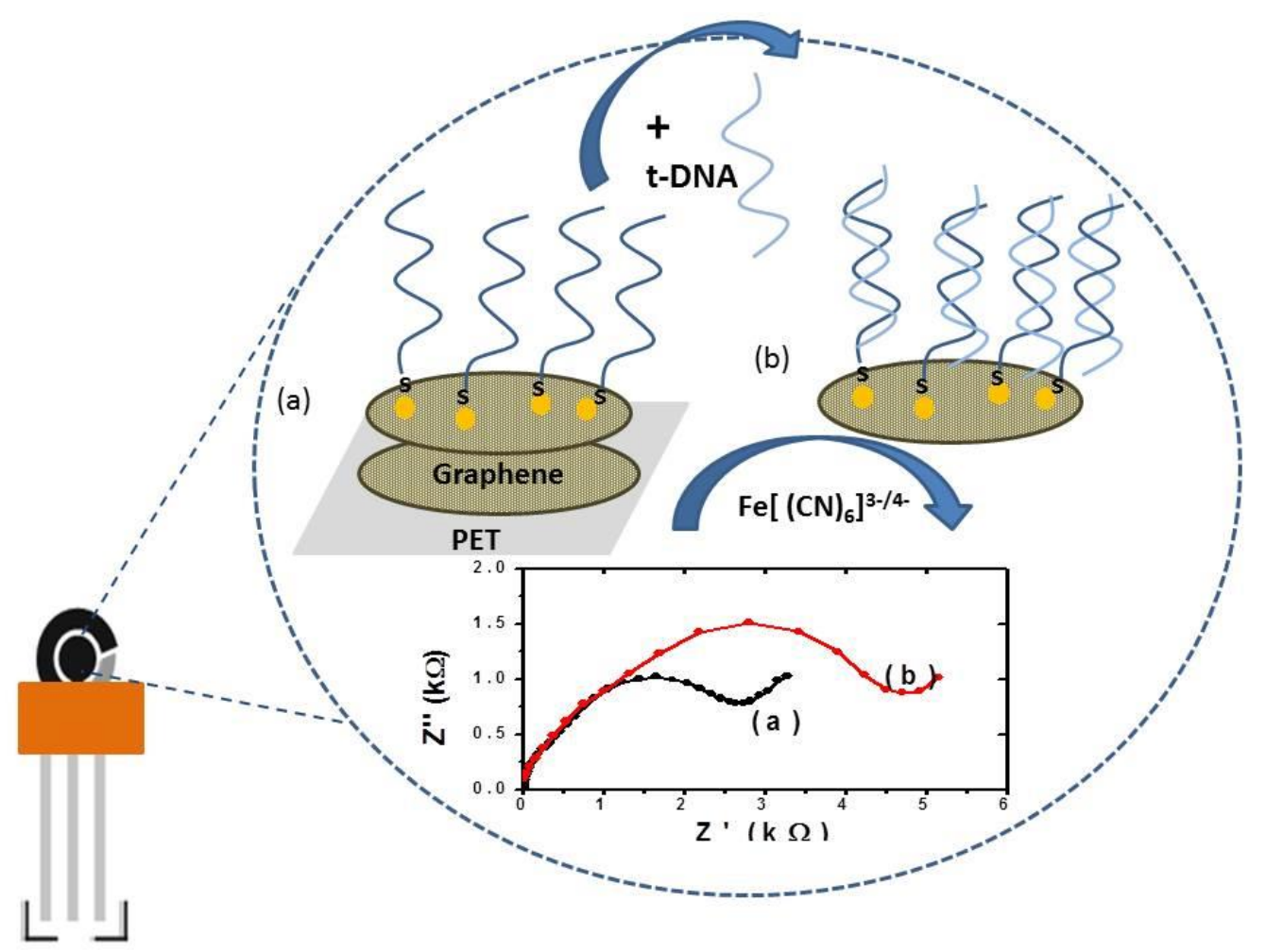

Figure 1: DNA sensing principle. After stamping on the PET substrates, rGO/AuNPs /ssDNA is incubated with the target ssDNA. DNA duplex formation causes an increase in impedance that is related with the amount of analyte.

\section{EXPERIMENTAL SECTION}

\subsection{Oligonucleotides}

Synthetic oligonucleotides were obtained for Sigma-Aldrich. The target sequence employed corresponds to a region characteristic of the ECHO virus (Coxsackie virus B3).

Probe: 5'-Thi CCTGAATGCGGCTAATCCTA - 3'

Target: 5'-TAGGATTAGCCGCATTCA - 3'

\section{Non-Complementary DNA : 5' GCATCATAGGCAGTCAGGT 3'}

Oligonucleotide solutions were prepared in TE buffer, $\mathrm{pH} 8$ (10mM Tris-HCl buffer solution, $1 \mathrm{mM}$ in EDTA) and maintained at $-20^{\circ} \mathrm{C}$. Working solution of the oligonucleotide probe was made in $0.1 \mathrm{M}$ Tris. $\mathrm{pH} 7.2$ buffer, while thiol labeled oligonucleotide target strand was diluted in a $2 \times \mathrm{SSC}$ buffer (300mM sodium chloride/30mM sodium citrate),pH 7.2. This solution was stored at $4^{\circ} \mathrm{C}$. 


\subsection{Chemicals and equipment}

The GO (Graphenea Graphene Oxide, $4 \mathrm{mg} / \mathrm{ml}$ ) was purchased from Graphenea Inc (Cabridge, MA 02142, U.S.A). Sodium Citrate $\left(\mathrm{HOC}(\mathrm{COONa})\left(\mathrm{CH}_{2} \mathrm{COOH}\right)_{2}\right.$, Sodium chloride $(\mathrm{NaCl})$, ascorbic acid (C6H8O6), BSA (Bovine serum albumin), Trizma® base $\left(\mathrm{NH}_{2} \mathrm{C}\left(\mathrm{CH}_{2} \mathrm{OH}\right)_{3}\right)$ and $\mathrm{Gold}(\mathrm{III})$ chloride hydrate $(\mathrm{HAuCl} \cdot \mathrm{H} 2 \mathrm{O})$ were purchased from Sigma-Aldrich Quimica SL (Madrid, Spain). Potassium Haxacyanoferrate $\mathrm{K}_{3}\left[\mathrm{Fe}(\mathrm{CN})_{6}\right] /$ $\mathrm{K}_{4}\left[\mathrm{Fe}(\mathrm{CN})_{6}\right]$, was purchased from Panreac Quimica S.L.U. Rest of the general chemicals were purchased from Sigma Aldrich (Spain). All chemicals were of analytical grade and used as received and All the aqueous solutions were prepared in Milli-Q water.

Characterization of the materials, composites and prints were performed using Scanning Electrochemical Microscopy FEI Quanta 650 FEG ESEM and FEI Magellan 400L (high resolution, HR-SEM) (The Netherlands), High resolution transmission electron microscopy (TEM) FEI Tecnai F20, , ultra-violet visible spectroscopy (UV-Vis),Cary 4000 UV-Vis Spectrophotometer, Agilent technologies, X-ray photoelectron Sepctroscopy (XPS), SPECS PHOIBOS 150 analyser (SPECS GmbH, Berlin, Germany).

Xerox ColourQube 8570 wax printer (compatible with Windows ${ }^{\mathrm{TM}}$, MacOS ${ }^{\mathrm{TM}}$ and UNIX) and Corel Draw software, Screen printing was performed using DEK 248 semi-automatic creenprinter (England) and the electrochemical studies were carried out using Autolab302 Potentiostat/galvanostat PGST30 with the software GPES for cyclic voltammetry and FRA for impedace measurements. 


\subsection{Methods}

\section{Synthesis of $r G O$}

$10 \mathrm{mg} / \mathrm{mL}$ Graphene oxide (GO) was provided by angstrom materials. It was reduced by exposing $100 \mathrm{~mL}$ of $1 \mathrm{mg} / \mathrm{mL}$ GO (solution to $100 \mathrm{mg}$ of ascorbic acid in an autoclave at $121^{\circ} \mathrm{C}$ for $45 \mathrm{~min}$.

AuNPs synthesis and conjugation with probe single-stranded DNA (ssDNA)

$16 \mathrm{~nm}$ sized AuNPs were synthesized using turkevich's method (Turkevich, J. et al, 1951) . Briefly, $50 \mathrm{~mL}$ of $1 \% \mathrm{HAuCl}_{4}$ solution was heated in an Erlynmeyer flask under vigorous stirring until boiling starts. Then, $1.25 \mathrm{~mL}$ of $1 \%$ sodium citrate was added while stirring continued. The reaction was kept under same conditions until $10 \mathrm{~min}$ and then the heating was stopped andthe reaction was let to cool. The color of the solution changes from deep blue to wine red, indicatingAuNPs formation. AuNPs suspension was stored at $4^{\mathrm{C}} \mathrm{C}$ protected from light until further use.

\subsubsection{Conjugation of AuNPs with probe DNA (ssDNA)}

The particles were then conjugated with the thiol modified ssDNA probe sequence using the protocol described and pioneered by Mirkin et al (Mirkin, C. A. et al, 1996). For this, $190 \mu \mathrm{L}$ of AuNPs were mixed with $10 \mu \mathrm{L}$ of $1500 \mu \mathrm{g} / \mathrm{mL}$ thiolated sequence at $250 \mathrm{rpm}$ for $20 \mathrm{~h}$ at 25 C. Later $50 \mu \mathrm{L}$ of $10 \mathrm{mM}$ phosphate buffer $(\mathrm{pH} 7) / 0.1 \mathrm{M} \mathrm{NaCl}$ was added to the above solution and let it stand for $44 \mathrm{~h}$. Finally a centrifugation step at $14000 \mathrm{rpm}$ at $4{ }^{\circ} \mathrm{C}$ for $20 \mathrm{~min}$ was carried out to extract the conjugated DNA which was reconstituted in $200 \mu \mathrm{L}$ Mili-Q water for further use. Later, $0.1 \%$ BSA solution in milli-Q water was added to graphene and conjugated AuNPs in separate eppendorf tubes and mixed for $1 \mathrm{~h}$ at 600rpm at room temperature and $4^{\circ} \mathrm{C}$ respectively. 


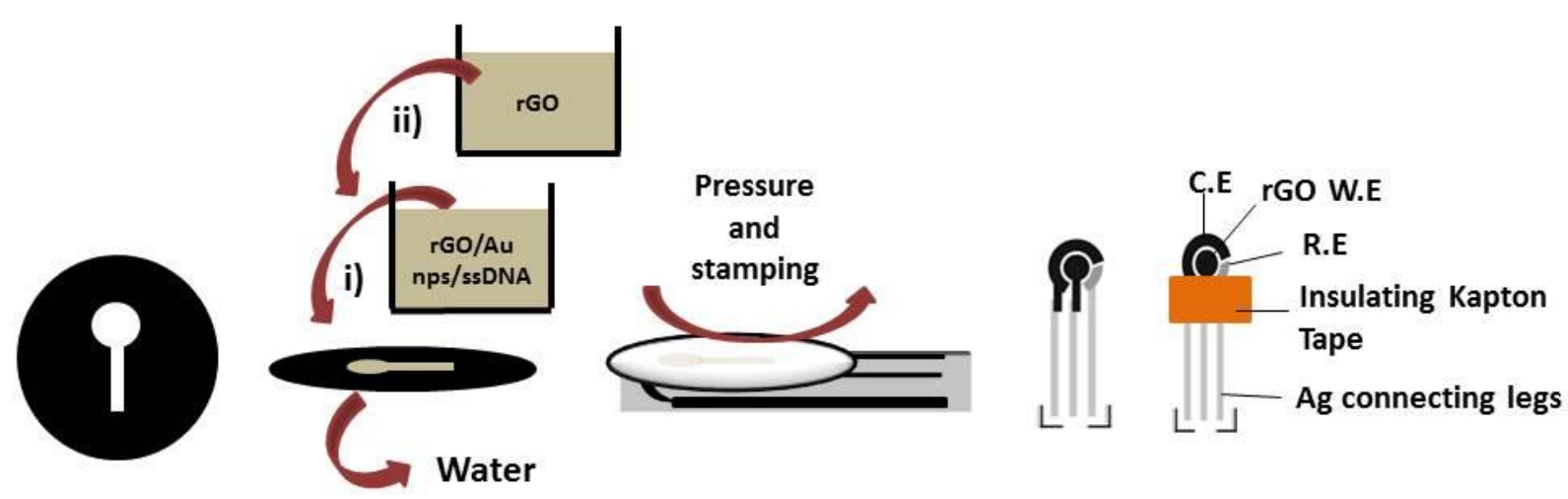

(a)

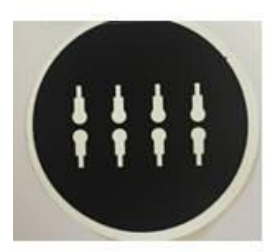

(b)

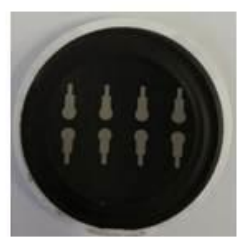

(c)

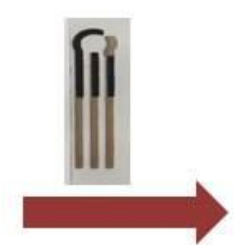

(d)

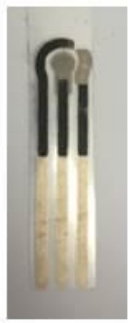

(e)

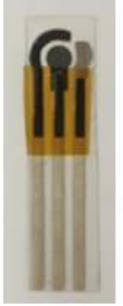

Figure 2 : Schematic of the printing strategy (top) pictures of the sensing platform (bottom). (a) wax printed design over the filter membrane; (b) sequential filtering of the two solutions to form two layers; (c) stamping of the filtered layer; (d) fully-printed electrode consisting of fully functional 3 electrodes for electrochemical measurements; (e) attachment of Kapton layer for insulation.

\section{$r G O$ and $r G O / A u N P s / s s D N A$ patterning}

A hydrophilic nitrocellulose membrane (purchased from Merck) with a pore size of $25 \mu \mathrm{m}$ and diameter of $47 \mathrm{~mm}$ was used for making patterns using the wax printer followed by filtration of the water based solutions were done- i) First layer of 3mL solution containing 1.7 $\mathrm{mL}$ rGO $(1.7 \mathrm{~mL} ; 0.25 \mathrm{mg} / \mathrm{mL})$ hand mixed with $300 \mu \mathrm{L}$ AuNPs/ssDNA was filtered and then ii) second layer was formed by adding $10 \mathrm{~mL}$ of $0.6 \mathrm{mg} / \mathrm{mL}$ rGO solution very carefully (not to disturb the already filtered layer) over the first layer. This was removed from the vacuum machine and then stamped over the already patterned (counter and reference) screen printed electrodes. Figure 2(a-e) shows the schematic printing steps (top) and corresponding pictures of the sensing platform (bottom). The procedure is done in the following way: at first, a specific design is wax printed onto the $25 \mathrm{~nm}$ pore sized filter membranes (a), (b) which is then used for filtration of two solutions sequentially (First the mixture of rGO/AuNPs/ssDNA 
and on top just rGO), (c) this filtererd membrane is then attached to the desired substrate (PET) and passed through the rollers that are already installed in the wax printer to provide the pressure. The substrate is made ready for this step by printing the other electrodes prior to wax stamping, that consisted of 2 steps (i) printing of silver layer for better conductivity and (ii) printing of counter layer (carbon) and reference layer $(\mathrm{Ag} / \mathrm{AgCl})$. (R.E and C.E respectively) using a screen-printer. the patterns were left to dry at $100^{\circ} \mathrm{C}$ overnight to dry the solvents The working area however was left blank intentionally for stamping of Graphene or Graphene composites later. (d) is the printed electrode that is insulated with the kapton tape (e), ready to use for further measurement. Without any further modifications, these electrodes were used for electrochemical tests and biosensing. For hybridization step, $30 \mu \mathrm{L}$ of different concentrations of complementary and non-complementary DNAs (in 2 x SSC buffer, pH 7.2) (De la Escosura-Muñiz et al., 2007) were added to the working electrode of the sensor and incubated for $1 \mathrm{~h}$ at room temperature. It was then washed using PBS solution $\mathrm{pH} 7.4$ before obtaining the electrochemical response.

Long-term stability of the sensors was evaluated by storing rGO/AuNPs/ssDNA electrodes at $4^{\circ} \mathrm{C}$ when not used and hybridizing with the complementary ssDNA after $0,5,10,15$ and 20 days.

\section{Electrochemical set-up}

Once the electrodes were fabricated, their electrochemical performance was evaluated. The electrochemical studies of the printed electrode were always performed in a solution of $10 \mathrm{mM}$ PBS (Phosphate Buffer Saline) containing $20 \mathrm{mM}\left[\mathrm{Fe}(\mathrm{CN})_{6}\right]^{3-/ 4-}$ as redox active probe. Firstly, Cyclic Voltammetry was performed within the voltage range -0.5 to $0.8 \mathrm{~V}$ vs $\mathrm{Ag} / \mathrm{AgCl}$ that provided us the oxidation and reduction peaks of $\mathrm{Fe}(\mathrm{III}) /(\mathrm{II})$ which were taken as the reference peaks. It involved a preliminary study on the graphene concentrations as well as the 
behavior of different modified printed electrodes. Later, DNA quantification studies were made using Electrochemical Impedance Spectroscopy (EIS) with the software FRA, carried out in the frequency range of $1000 \mathrm{~Hz}$ to $0.05 \mathrm{~Hz}$. For all the measurements, $200 \mu \mathrm{L}$ of the electrolyte solution were placed on the electrode area (covering all the electrodes) under room temperature without interruption. The electrodes were connected with the potentiostat using a homemade edge connector module.

\section{RESULTS AND DISCUSSION}

\subsection{Morphological characterizations}
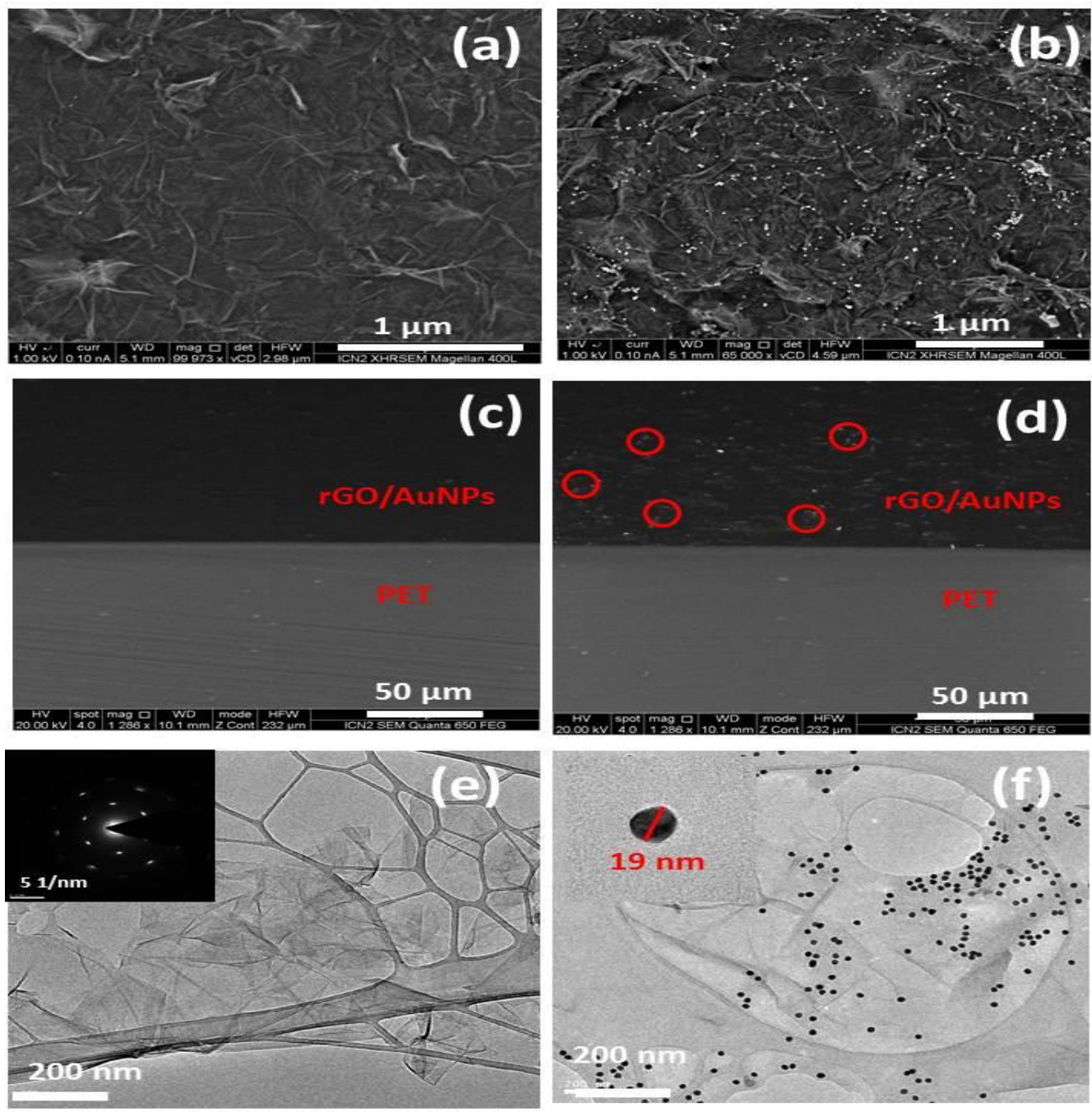

Figure 3 : :Optical characterizations. HR-SEM images of the top view (a and b), cross sectional view (c and d), TEM images (e and f) of printed rGO and AuNps/rGO respectively. Insets SAED patters of rGO fig. 3(e) and AuNps size fig. 3(f) 
Figure 3 (a and b) shows the high resolution scanning electron microscopy (HR-SEM) top view images of printed rGO and rGO/AuNPs, whereas Figure 3 (c and d) shows SEM images corresponding to cross sectional view of the prints over the PET susbtrate. It was observed that the two layers were placed uniformly over the desired area of the electrode and that the conjugated AuNPs appeared only on the surface and not in the bulk.

This was a strategy adopted to have mainly two benefits a) uniform deposition of the conjugated nanoparticles throughout the working electrode and b) to minimize quantity of the biorecognition element used. Another option was to use the rGO/AuNPs/ssDNA directly as the working electrode instead of filtering 2 layers. The transmission electron microscopy (TEM) image of graphene and its mixture with AuNPs is shown in Figure 3 (e and $\mathrm{f}$ respectively). It shows a thin and transparent morphology of the graphene nanosheets along with large size 3(e) and uniform AuNPs distributions in 3(f). The selected area electron diffraction pattern confirms the formation of graphene (inset). From Figure 3 (f) inset, it can be seen that AuNPs have a diameter of $\sim 20 \mathrm{~nm}$ and are uniformly attached/adsorbed onto the graphene sheets.

X-ray Photoelectron spectroscopy was utilized further to evaluate the elemental ratios of the binding states of the materials, as shown at Figure 4 (a-e). To prepare it, layer of GO, rGO and $\mathrm{rGO} / \mathrm{AuNPs} / \mathrm{ssDNA}$ were filtered on different nitrocellulose filter membranes and used directly for the measurement. A very high degree of oxidation is shown for GO as seen from its C 1s spectra, Figure 4(b). It shows the different carbon oxygen bonds like Carboxyl $(289 \mathrm{eV})$, epoxide/hydroxl bonds $(286.7 \mathrm{eV})$. These peaks were changed after the reduction of GO in ascorbic acid was performed. In Figure 4 (c), a highest peak at $284.8 \mathrm{eV}$ was observed after the reduction procedure which corresponds to the graphitic carbon i.e. the energy of $\mathrm{sp}^{2}$ C-C bonds along with drastic decrease in all the peaks related to the oxygen species (Hossain, M. F. and Park J. Y., 2014; Arul, R et al, 2016; Xu, J. et al, 2017; Yu, X. et al, 20018) . Also, 
mixture of $\mathrm{rGO} / \mathrm{AuNPs} / \mathrm{ssDNA}$ with BSA (used as blocking reagent for avoiding unspecific (used as blocking reagent for avoiding unspecific adsorptions) was studied using this technique. Two obvious peaks observed at $84 \mathrm{eV}$ and $87.6 \mathrm{eV}$ for $\mathrm{Au} 4 \mathrm{f} 7 / 2$ and $\mathrm{Au} 4 \mathrm{f}_{5 / 2}$ respectively with a difference of $3.6 \mathrm{eV}$ is an indication for the presence of Au nanoparticles , Figure 4(e) (H H Mevold, A. et al, 2015; Krishnan, G. and John S. A., 2015; Govindaraju, S. et al, 2017) was observed. Figure 4 (d) shows the $N$ 1s spectra of the mixture that corresponds to tertiary amines at $400.3 \mathrm{eV}$ and protonated primary amines at $401.6 \mathrm{eV}$ (Zhang, F. and Srinivasan M. P., 2004; Yang, Y. et al 2009; Stevens J. S. et al, 2013) most likely coming from the BSA that is used to modify Graphene and AuNPs.adsorptions) was studied using this technique. Two obvious peaks observed at $84 \mathrm{eV}$ and $87.6 \mathrm{eV}$ for $\mathrm{Au} 4 \mathrm{f} 7 / 2$ and $\mathrm{Au}$ $4 \mathrm{f}_{5 / 2}$ respectively with a difference of $3.6 \mathrm{eV}$ is an indication for the presence of $\mathrm{Au}$ nanoparticles , Figure 4(e) (H H Mevold, A. et al, 2015; Krishnan, G. and John S. A., 2015;
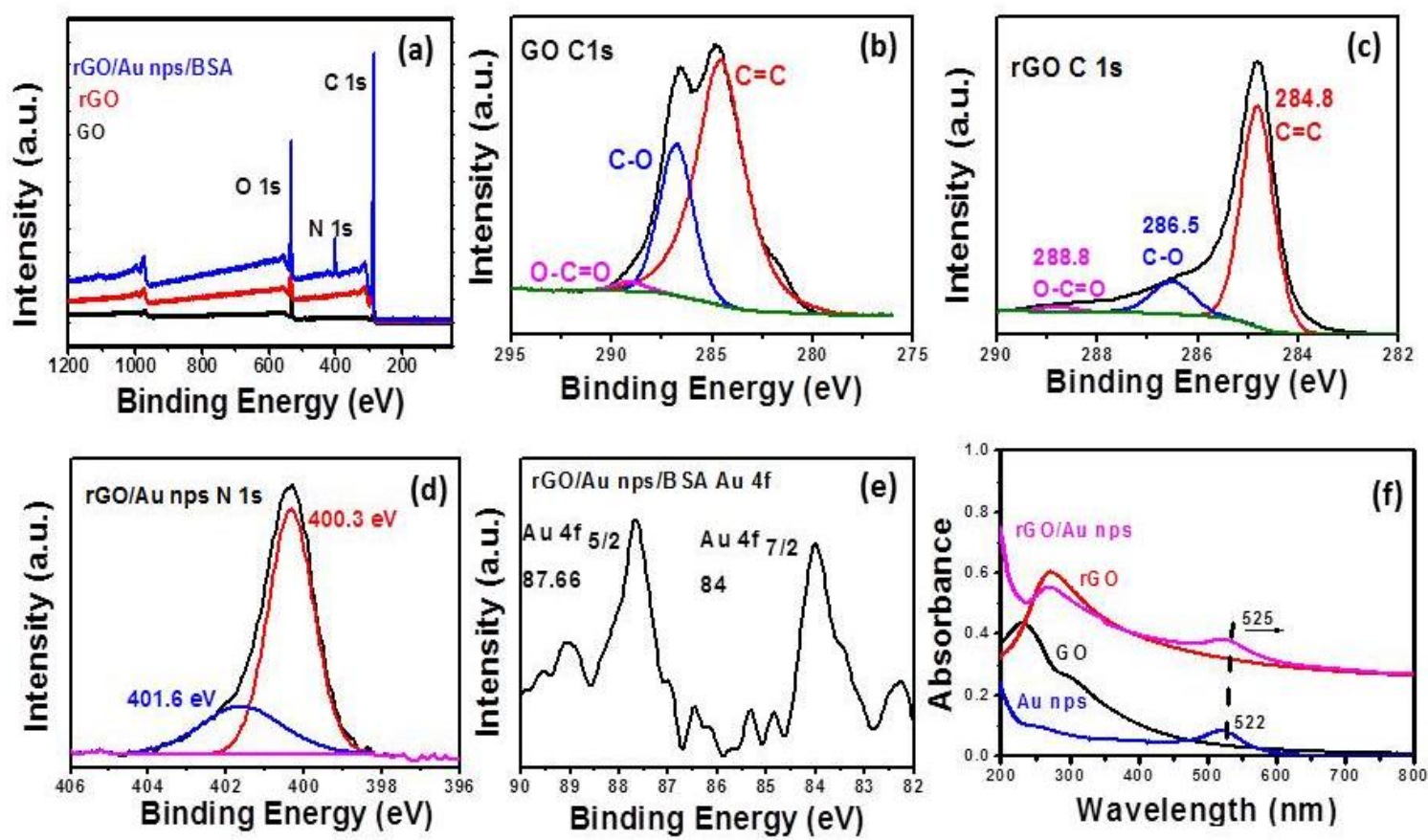

Figure 4 : X-ray Photoelectron spectroscopy (a)overall spectra of GO, rGO and rGO/AuNPswith BSA, core level XPS spectra of $\mathrm{C}$ 1s of (b) GO and (c) rGO, (d)N 1s and (e)Au $4 \mathrm{f}$ of rGO/Au nps modified with BSA . (f) UV-Visible spectra of GO, rGO, AuNPs and rGO/AuNPs 
Govindaraju, S. et al, 2017) . Figure 4 (d) shows the N 1s spectra of the mixture that corresponds to tertiary amines at $400.3 \mathrm{eV}$ and protonated primary amines at $401.6 \mathrm{eV}$ (Zhang, F. and Srinivasan M. P., 2004; Yang, Y. et al, 2009; Stevens J. S. et al, 2013; Yu, B. et al, 2014) most likely coming from the BSA that is used to modify Graphene and AuNPs. Figure 4(f) shows the UV-vis spectra of GO, rGO and rGO/AuNPs with BSA. Reduction of GO to rGO is visible from the spectra where GO shows the typical humps at 230 and $300 \mathrm{~nm}$ that corresponds to $\pi-\pi^{*}$ transitions of $\mathrm{C}=\mathrm{C}$ bonds and $\mathrm{n}-\pi^{*}$ transitions of $\mathrm{C}=\mathrm{O}$ bonds respectively and changes to only one peak at $273 \mathrm{~nm}$ due to a red shift and the peak at $300 \mathrm{~nm}$ is disappeared indicating the formation of reduced graphene oxide. The presence of AuNPs can be confirmed with the peak spotted at $525 \mathrm{~nm}$, however, after modifying the particles with BSA, the peaks shifted slightly to $528 \mathrm{~nm}$ suggesting successful modification with the protein. BSA is a protein that consists of The interaction of BSA with AuNPs can be explained by the hydrophobic interactions, the thiol-Au interactions (thiol or disulfide groups present in the amino acids of BSA; cysteine) or due to the interaction of amines or carboxylate groups with AuNPs (Zhang, Z. et al 2011; Amouzadeh Tabrizi, M. et al, 2014; Binaymotlagh, R. et al, 2016) .

\subsection{Electrochemical Testing}

\subsubsection{Electrodes characterization using Cyclic voltammetry $(C V)$}

Cyclic voltammetry (CV) was initially employed to test the performance of the electrodes using $5.0 \mathrm{mM}\left[\mathrm{Fe}(\mathrm{CN})_{6}\right]^{3-4-} / 0.1 \mathrm{M}$ PBS as redox probe. At first, different concentrations of GO were tested in order to optimize the best thickness needed for conductivity and robustness. Figure 5 (a) shows the optical images (inset) and the CV for rGO filtered ranging from 0.1 to $1 \mathrm{mg} / \mathrm{mL}$. It was observed that at higher concentrations $(>0.6 \mathrm{mg} / \mathrm{mL})$, the prints were non-uniform and uneven (inset) and the oxidation/reduction peaks shifted towards more positive/negative potential respectively without any considerable increase in the current 
values. At low concentrations $(<0.6 \mathrm{mg} / \mathrm{ml})$, the current values where extremely low making it inefficient for further measurements ( $\mathrm{CV}$ in Figure 5a). Consequently. $0.6 \mathrm{mg} / \mathrm{mL}$ was chosen as optimum concentration for all the final measurements. Next, study on electrochemical behavior of the optimized electrode was continued using CV. Figure 5(b) shows that the peak currents $\left(\mathrm{Ip}_{\mathrm{a}}\right.$ and $\left.\mathrm{Ip}_{\mathrm{c}}\right)$ linearly increase with the increasing scan rate. This is indicative of the fact that the ongoing electrochemical process of $\mathrm{Fe}$ (II) to $\mathrm{Fe}$ (III) was diffusion controlled. Also, the shift in oxidation/reduction peak positions with increasing scan rates demonstrates that the process was quasi- reversible since in a reversible process, the peak position is independent of the scan rate. This linear dependency of peak potential was plotted against the square root of scan rate, given in Figure 5c. Figure 5(d) are the signals obtained from electrodes of different printed materials. The signal decreases after the presence of ssDNA due to electrostatic repulsion from negatively charged DNA strands. This was decreased further after modifying the material with BSA, evidencing successful blocking of free sites that could cause non-specific adsorption. Later, after addition of $1 \mu \mathrm{M}$ target ssDNA, the current was seen decreasing more due to enhanced repulsion between the negatively charged DNA and negative ions from the electrolyte that hinders the charge transfer at electrode/electrolyte interface. 

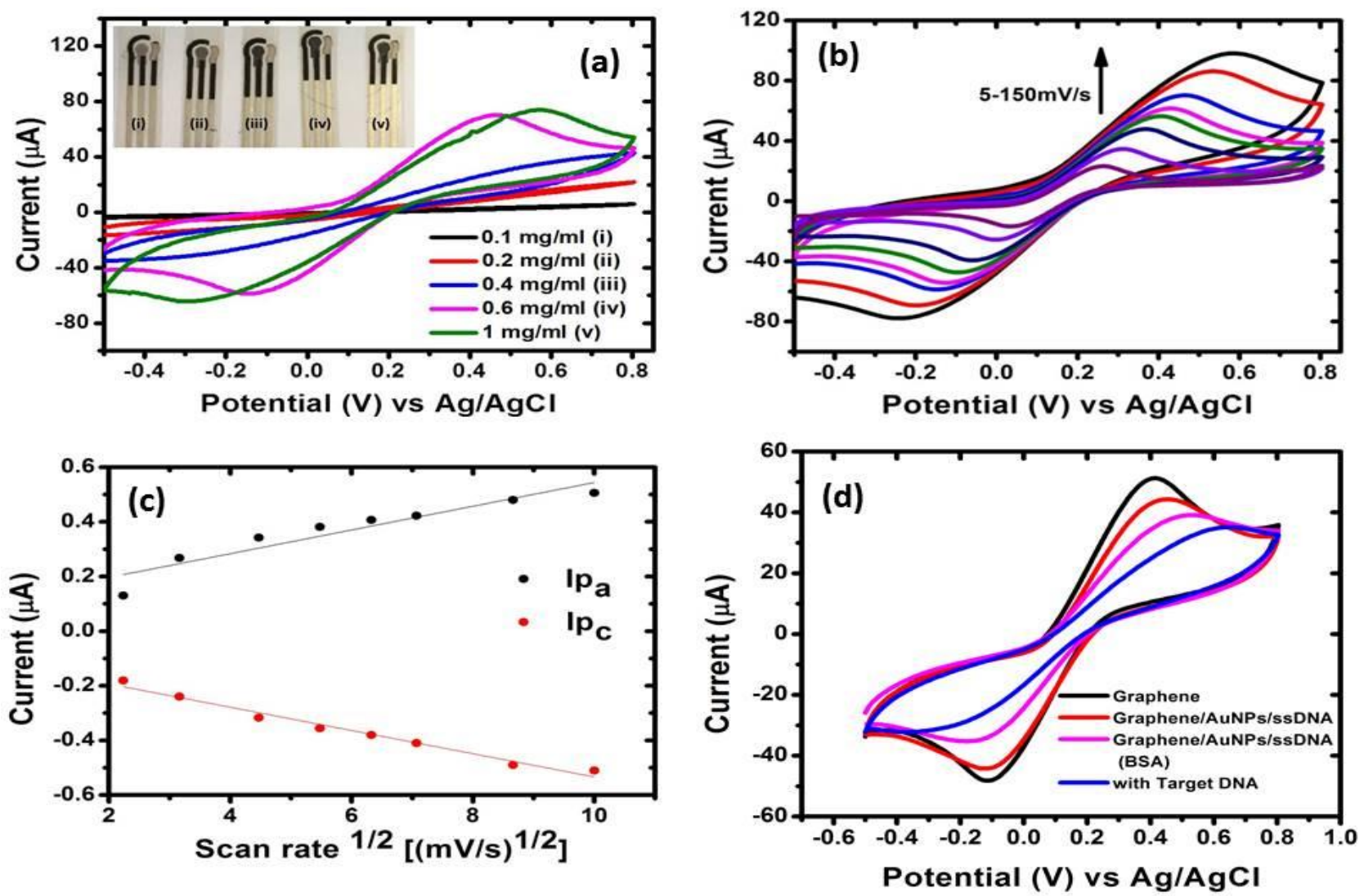

Figure 5 : (a) optimization of the rGO concentrations from 0.1 to $1 \mathrm{mg} / \mathrm{ml}(\mathrm{i}-\mathrm{v})$ with the images in the inset and their corresponding CV response, CV response of the electrode studied at (a) different scan rates from 5 to $150 \mathrm{mV} / \mathrm{s} \mathrm{b}$ ), Plot of Current vs the square root of scan rate. Furthermore, at figure (c) is the response of different materials and target analytes at $50 \mathrm{mV} / \mathrm{s}(\mathrm{d})$

\subsubsection{DNA quantification using Electrochemical Impedance Spectroscopy (EIS)}

After optimizing the graphene electrode and its quality testing, the electrodes were further used for performing impedance measurements. Electrochemical impedance spectroscopy (EIS) is very useful electrochemical technique that is generally performed to obtain more sensitive information about the changes and interactions going on at the interface. One of the way to interpret the data is through the Nyquist plot which typically consists of a semicircle at high frequency regions corresponding to blocking of the transferred charges at electrode/electrolyte interface. This is called the charge transfer resistance $\left(\mathrm{R}_{\mathrm{CT}}\right)$ which can be calculated by directly measuring the diameter of the semicircle. At high frequency regions it shows a line with a slope of around $45^{\circ}$ which demonstrates a diffusion controlled process. 
This typical behavior was exhibited by our graphene electrodes (as displayed in Figure 6a. Graphene electrodes showed a very low charge transfer resistance of $1.3 \mathrm{k} \Omega$ which was seen increasing after modifying its surface by addition of conjugated AuNPs (rGO/AuNPs/ssDNA) to $2.7 \mathrm{k} \Omega$. This correlates with the $\mathrm{CV}$ results and the explanation that the coated layer was blocking the electron transfer from $\left[\mathrm{Fe}(\mathrm{CN})_{6}\right]^{3-14-}$ to the electrode surface as a result of electrostatic repulsion. It was observed that AuNPs treated with BSA exhibited larger Rct value than without the treated ones. This implied that the free sites on the synthesized AuNPs were successfully covered and the non-specific adsorption/attachment was minimized if not completely eliminated. Figure 6(a) shows the increase of resistance observed with increasing concentrations of the target probe from 0.01 to $25 \mu \mathrm{M}$ increases of 3.5, 4.7, 5.6, 6.5 and 7.6 $\mathrm{k} \Omega$ were observed for $0.01,0.1,1,10,20 \mu \mathrm{M}$ target ssDNA respectively. . For normalizing the response of the different electrodes, the increase in Rct for each sensor before and after the hybridization is considered as the analytical signal. Figure 6(b) gives the quantitative information on the increase in the value of such analytical signal with the amount of target ssDNA. A logarithmic range of response from 0.01 to $20 \mu \mathrm{M}$ was observed, adjusted to the following equation:

$$
\text { Increase in } \mathrm{R}_{\mathrm{ct}}(\mathrm{K} \Omega)=148.82 \ln [\text { conc. ssDNA }(\mu \mathrm{M})]+1344.5
$$

with a correlation coefficient (r) of 0.994 , with an average relative standard deviation (RSD) of $13 \%$. A limit of detection (LOD, calculated as the analyte concentration giving a signal equal to the blank signal +three times its standard deviation) of $0.18 \mathrm{nM}$ of ssDNA is estimated. A linear range from 0.01 to $20 \mu \mathrm{M}$ was observed with a correlation coefficient (r) of 0.97. Limit of detection (LOD, calculated as the analyte concentration giving a signal equal to the blank signal + three times its standard deviation) of $2.5 \mathrm{nM}$ with an average relative standard deviation (RSD) of $13 \%$ was calculated. A non-significant increase in resistance was observed with the addition of blank buffer and $0.1 \mu \mathrm{M}$ non complementary ssDNA, demonstrating the specificity ssDNA due to electrostatic repulsion from negatively charged 
DNA strands. This was decreased further after modifying the material with BSA, evidencing successful blocking of free sites that could cause non-specific adsorption. Later, after addition of $1 \mu \mathrm{M}$ target ssDNA (as an example), the current was seen decreasing more due to enhanced repulsion between the negatively charged DNA and negative ions from the electrolyte that hinders the charge transfer at electrode/electrolyte interface. Long-term stabilty study results suggest that the sensor performance remain unaffected during at least up to three weeks (see supporting information). Longer times were not evaluated in this preliminary work.

The proposed biosensor showed comparable or enhanced performance than recently reported DNA sensors on conventional screen printed electrodes, where detection limits at the $\mathrm{nM}$ levels are achieved i.e.4.7nM for ebola Virus (Ilkhani, H. and Farhad S., 2018) and 35 and 21nM for influenza genes (Subak, H. and Ozkan-Ariksoysal D., 2018). Although, modifying graphene surfaces prior to printing and later DNA detection has result in sensors with higher sensitivities, even at fM levels, (Chen, M. Et al, 2016; Chen, S. et al, 2016) ; , our approach exhibit clear advantages in terms of integration, simplicity and low time of analysis It must also be noted that in this work, no additional conducting layer has been utilised for transfer of charges:graphene is the sole carrier for conduction as well as for anchoring AuNPs and ssDNA. This also opens the possibility directly adsorbing probe ssDNA (labelled or un labelled) via $\pi-\pi$ bonding onto graphene substrates and checking the elecrtrochemical or optical signals. 

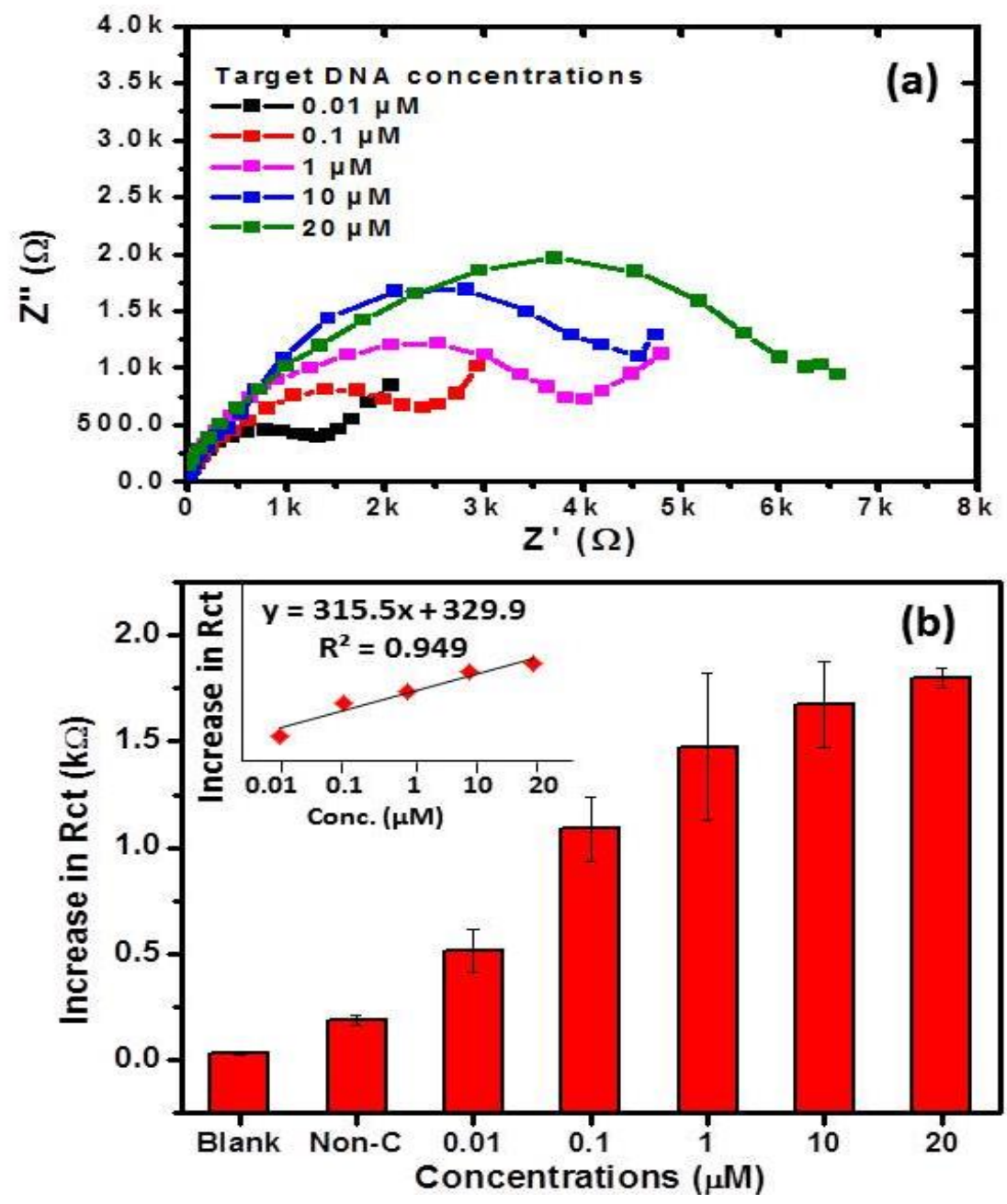

Figure 6: a) Impedimetric response of the electrode towards different concentrations of the complementary DNA (0.01 to 20 $\mu \mathrm{M}$ ) on different electrodes and (b) the change of resistance for different target ssDNA concentrations as well as for the blank and the negative control

\section{CONCLUSION}

An innovative strategy of printed sensing platform that requires only one step modification of the working electrode has been proposed and demonstrated. A composite containing the electrode material (rGO) as well as AuNPs connected with the biorecognition element (ssDNA), was stamped onto a PET substrate.Such strategy eliminates the need of conventional modification steps of the electrode prior to testing. The electrode properties and materials were characterized and the printing procedure was carefully optimized. ssDNA characteristic of a virus was selected as model analyte, for the demonstration of the proof-ofconcept, based on changes in the impedimetric signal of the electrode, reaching a detection 
limit of $2.5 \mathrm{nM}$. The performance of the system is comparable with those previously reported using conventional screen-printed carbon electrodes, but with clear advantages in terms of simplicity, integration and time of analysis. This successful proof-of-concept can be extended to other affinity biosensors, taking advantage of the integration of the bioreceptor (antibody, enzyme, etc) on the sensor surface. Such ready-to-use biosensor would lead to a one-step electrochemical detection.

\section{ACKNOWLEDGMENTS}

We acknowledge support from the Spanish MINECO under projects MAT2014-52485-P and PCIN-2016-066 (program Euronanomed 2) and from Secretaria d'Universitats i Recerca del Departament d'Economia i Coneixement de la Generalitat de Catalunya (Grant 2014 SGR 260). This work is also funded by the CERCA Programme / Generalitat de Catalunya. ICN2 is supported by the Severo Ochoa program from Spanish MINECO (Grant No. SEV-2013-0295). Bhawna Nagar also acknowledges Autonomous University of Barcelona (UAB) for the possibility of performing this work inside the framework of Material Science (Department of Chemistry) PhD Programme.

\section{REFERENCES}

Arul, R., Oosterbeek R., Robertson J., Xu G., Jin J.and Simpson C., 2016, Carbon, 99, 423 431

Baptista-Pires, L., Mayorga-Martínez C. C., Medina-Sánchez M., Montón H.and Merkoçi A. 2016. ACS Nano 10(1), 853-860.

Binaymotlagh, R., Hadadzadeh H., Farrokhpour H., Haghighi F. H., Abyar F. and MirahmadiZare S. Z., 2016. MATER CHEM PHYS , 177: 360-370.

Bo, X., Zhou M. and Guo L. 2017. Biosens. Bioelectron, 89, 167-186.

Bollella, P., Fusco G., Tortolini C., Sanzò G., Favero G., Gorton L. and Antiochia R., 2017. Biosens. Bioelectron, 89, 152-166.

Chen, M., Hou C., Huo D., Bao J., Fa H. and Shen C., 2016. Biosens. Bioelectron, 85, 684691.

Chen, S., Frank Cheng Y. and Voordouw G., 2018. Sens. Actuators, B, 262, 860-868.

Chen, X.-m., Wu G.-h.,. Jiang Y.-q, Wang Y.-r.and Chen X., 2011. Analyst, 136(22), 46314640 . 
De la Escosura-Muñiz, A., González-García, M.B., Costa-García, A. 2007. Biosensors and Bioelectronics 22, 1048-1054.

Dubal, D. P., Nagar B., Suarez-Guevara J., Tonti D., Enciso E., Palomino P. and GomezRomero P., 2017. Materials Today Energy 5: 58-65.

Geim, A. K. and Novoselov K. S., 2007.." Nat Mater., 6, 183.

Govindaraju, S., Ankireddy S. R., Viswanath B., Kim J. and Yun K., 2017. Sci Rep., 7, 40298.

H H Mevold, A., Hsu W.-W., Hardiansyah A.,. Huang L.-Y, Yang M.-C., Liu T.-Y., Chan T.Y., Wang K.-S., Su Y.-A., Jeng R.-J., Wang J. and Wang Y.-L., 2015. Nanoscale Res Lett, $10,397$.

Hossain, M. F. and Park J. Y., 2014. Electroanalysis, 26(5), 940-951.

Huang, T.Y., Huang, J. H., Wei, H.Y., Hoa, K.C., Chu, C. W., 2013. Biosens. Bioelectron, 43, 173-179.Ilkhani, H. and Farhad S. 2018. Anal. Biochem., doi: 10.1016/j.ab.2018.06.010

Justino, C. I. L., Gomes A. R., Freitas A. C., Duarte A. C. and Rocha-Santos T. A. P., 2017.

TrAC, Trends Anal. Chem., 91, 53-66

Krishnan, G. and John S. A., 2015. RSC Adv., 5, 42369-42375

Lee, H. C., Liu W.-W., Chai S.-P., Mohamed A. R., Aziz A., Khe C.-S., Hidayah N. M. S. and Hashim U., 2017. RSC Adv., 7(26), 15644-15693.

Lee, J., Han T.-H., Park M.-H., Jung D. Y., Seo J., Seo H.-K., Cho H., Kim E., Chung J., Choi S.-Y., Kim T.-S., Lee T.-W. and Yoo S., 2016. Nat Commun., 7, 11791

Lee, S.-M., J.-H. Kim and J.-H. Ahn (2015). Mater. Today, 18(6), 336-344.

Li, J., Rossignol F. and Macdonald J., 2015. Lab Chip, 15(12), 2538-2558.

Li, X. and Zhi L., 2018. Chem. Soc. Rev. 47(9), 3189-3216.

Lin, L., Liu Y., Tang L.and Li J., 2011. Analyst, 136(22), 4732-4737.

Mattana, G. and Briand D., 2016. Mater. Today, 19(2), 88-99.

Mirkin, C. A., Letsinger R. L., Mucic R. C. and Storhoff J. J., 1996. Nature 382, 607.

Nagar B., Dubal. D. P., Pires L., Merkoçi A., and Gomez-Romero P., 2018. ChemSusChem 11(11), 1849-1856.

Novoselov, K. S., Geim A. K., Morozov S. V., Jiang D., Zhang Y., Dubonos S. V., Grigorieva I. V. and Firsov A. A., 2004. Nat Mater., 306(5696), 666.

Pumera, M., 2011. Mater. Today 14(7), 308-315.

Quesada-Gonzalez, D. and Merkoci A., 2018. Chem. Soc. Rev., 10.1039/c7cs00837f

Randviir, E. P., Brownson D. A. C. and Banks C. E. (2014). Mater. Today 17(9), 426-432.

Ray, W. J. and Joseph W. (2013). " Electroanalysis 25(1), 29-46.

Stevens, J.S., Luca. A. C., Pelendritis, M., Terenghi, G., Downes S., and Schroeder S.L.M., 2013. Surf. Interface Anal. 45(8), 1238-1246.

Seo, J.-H., Ling T., Gong S., Zhou W., Ma A. L., Guo L. J. and Ma Z., 2016. Sci Rep., 6: 24771.

Shao, Y., J. Wang, H.-X. Wu, J. Jun Liu, I. A. Aksay and Y. Lin (2010). Electroanalysis, 22(10), 1027 - 1036.

Singh, A., Sinsinbar G., Choudhary M., Kumar V., Pasricha R., Verma H. N., Singh S. P. and Arora K., 2013. Sens. Actuators, B, 185, 675-684.

Singh, E., Meyyappan M. and Nalwa H. S., 2017. ACS Appl Mater Interfaces , 9(40), 3454434586.

Søndergaard, R., Hösel M., Angmo D., Larsen-Olsen T. T. and Krebs F. C., 2012. Mater. Today 15(1), 36-49.

Subak, H. and Ozkan-Ariksoysal D., 2018. Sens. Actuators, B, 263, 196-207.

Tabrizi, M. A., Tavakkoli A., Dhand V., Rhee K. Y and. Park S.-J , 2014,. J Ind Eng Chem, 20(6): 4327-4331.

Turkevich, J., Stevenson P. C. and Hillier J. (1951). J. Discuss. Faraday Soc., 11, 55-75 
Xu, J., Li D., Chen Y., Tan L., Kou B., Wan F., Jiang W. and Li F., 2017. Nanomaterials $7(12), 450$.

Yang, Y., Wang J., Zhang J., Liu J., Yang X. and Zhao H., 2009. Langmuir, 25(19), 1180811814.

Yu, B., Wang X., Qian X., Xing W., Yang H., Ma L., Lin Y., Jiang S., Song L., Hu Y. and Lo S., 2014. RSC Adv, 4(60), 31782-31794.

Yu, X., Wu Q., Zhang H., Zeng G., Li W., Qian Y., Li Y., Yang G. and Chen M., 2018. Materials, 11(1), 38.

Zhang, F. and Srinivasan M. P., 2004. Langmuir 20(6), 2309-2314.

Zhang, Z., Chen H., Xing C., Guo M., Xu F., Wang X., Gruber H. J., Zhang B. and Tang J. , 2011. Nano Res. 4(6), 599-611 